\title{
Derechos humanos e imaginarios sociales modernos. Un enfoque desde las relaciones internacionales ${ }^{*}$
} Human Rights and Modern Social Imaginaries. An approach from International Relations.

\author{
Francisco JaVIER PEÑAS
}

Universidad Complutense de Madrid

RESUMEN. En este artículo se trata de situar el régimen de derechos humanos -aunque sólo el de los llamados derechos civiles y políticos- dentro del universo mental de los imaginarios sociales modernos que conforman nuestra forma de leer el mundo En estas páginas se sostiene que: (1) los derechos humanos no tienen fundamento filosófico posible (sólo la población a un ser trascendental que la filosofía ya no reclama); (2) uno de los ejes de estos imaginarios sociales modernos es el que se extiende desde la humanidad una (cosmópolis) hasta el estado soberano moderno; (3) el otro eje se despliega entre la civilización y la condición de salvaje, en un relato teleológico. Con estas premisas los derechos humanos, que sólo se entienden hasta el fondo, en una determinada tradición lingüística, pueden y deben ser usados, no como fundamentos universales de la acción, sino como armas de lucha.

Palabras clave: Derechos humanos; imaginarios sociales; relaciones internacionales; teoría política.
ABSTRACT. This article aims to set the human rights regimen -though only the regimen that refers to civil and political rights in the context of the mental universe of those social imaginaries that constitute our way of reading the world... In these pages I state that human rights have no fundamental philosophical foundation (in any case, only a transcendental being excluded from our philosophical thoughts), (2) that one of the axis of these modern social imaginaries is the one that deploys itself from the human kind as one (cosmopolis) to the sovereign state; and (3) the other axis stretches from civilization to barbarism, in a teleological narrative. With these in mind, human rights, that could only be understood totally inside a linguistic tradition, could and should be used, not as universal foundation of action, but as weapons for struggle.

Key words: Human rights; social imaginaries; international relations; political theory.

* Agradezco las críticas y comentarios de Itziar Ruiz-Giménez (Universidad Autónoma de Madrid) y de Ángela Iranzo (Universidad de los Andés, Bogotá). 
"No hay peor argumento contra una teoría cientifica o filosófica que señalar sus presuntas consecuencias políticamente perniciosas"

Hume

Los, hombres en todas partes, dan el nombre de virtud a aquellas acciones que entre ello se consideran dignas de alabanza; y llaman vicio a las que se consideran reprobables"

Locke

“...no es tan inverosímil que la posibilidad de verificar una propuesta, o de falsificarla... dependa del hecho de que hablamos el mismo lenguaje, usamos instrumentos análogos, tomamos las mismas medidas, etc.

De otra manera no nos entenderíamos. Este conjunto de premisas y paradigmas no lo hemos inventado desde cero, lo hemos heredado... está dentro de una situación... (como alguien) que tiene una historia, pertenece a una comunidad “

Vattimo $^{1}$

"La ética, de ser algo, es sobrenatural"

Wittgestein

Cada uno de los sustantivos y adjetivos del título de este trabajo necesita de una aclaración. Estas glosas serían, de desarrollarse hasta sus últimas consecuencias, un libro que contendría infinidad de libros, para utilizar la imagen borgesiana. Pues de lo que aquí se trata en el fondo es de la modernidad. Pero dentro de los límites de este artículo podemos esbozar lo que entendemos y connotamos con estos términos.

En primer lugar, cuando se habla en este trabajo sobre Derechos Humanos me refiero exclusivamente a los derechos civiles y políticos, que han sido ratificados por numerosos estados. No entramos, porque no son necesarios para nuestra investigación, en los llamados derechos de segunda, tercera, etc. generación. La tesis que aquí se mantiene es que tales derechos, aparte de ser, en un principio, muy necesarios y convenientes, son constructos humanos -contingente histórica y geográficamente- modernos $^{2}$, de un tiempo y de un lugar y que su universalidad inherencia no pueden, o no han podido ser fundamen-

\footnotetext{
${ }^{1}$ Vattimo, G., Adiós a la verdad, Barcelona, Gedisa, 2010, p. 80.

${ }^{2}$ El concepto de Dignidad humana, según Oliver Sensen ("Human dignity in historical perspective", European Journal of Politcal Theory, vol. 190, n 1, 2011, pp. 72 y ss.) como fuente de los derechos humanos ha variado con el tiempo y sólo aparece como la fuente de los derechos en el pensamiento contemporáneo (el autor llega a afirmar que en Kant tal concepto tiene más que ver con Cicerón que con la Carta y el Convenio de NN.UU.).
} 
tadas, ni filosófica ni antropológicamente ${ }^{3}$, más allá del pragmatismo, la convención ${ }^{4}$ o la necesidad.

Esta afirmación necesita de alguna aclaración. En primer lugar, hay que definir el uso que aquí se hace sobre el verbo fundamentar o el sustantivo fundamento. Según la Real Academia Española de la Lengua, se entiende por fundamentar: (1) establecer, asegurar y hacer firme algo y (2) echar los fundamentos o cimientos de un edificio. Según nuestra misma autoridad lingüística fundamento es: (1) principio y cimiento en que estriba y sobre el que se apoya un edificio u otra cosa, (2) seriedad, formalidad de una persona, (3) razón principal o motivo con que se pretende afianzar y asegurar algo, (4) raíz, principio y origen en que estriba y tiene su mayor fuerza algo no material y (5) fondo o trama de los tejidos. No queda claro en estas definiciones si fundamentar y, por tanto, fundamento o fundamentado (palabra que, por cierto no recoge la RAE independientemente sino como participio pasado del verbo fundamentar) es la acción de poner fundamentos o de establecer, con éxito, tales cimientos. "No han podido ser fundamentadas..." en este texto quiere decir lo segundo. No desconsidera los múltiples intentos de la filosofía moderna por establecer fundamentos o por describir la esencia de la naturaleza humana. Lo que se sostiene es que tales meritorios, en incluso brillantes, intentos no han tenido un éxito incontrovertible. Entre otras razones, porque generación tras generación de filó-

Parece que incluso desde el campo de la filosofía del Derecho se reconoce esta historicidad básica de los derechos humanos. Según A. Perez Luño ("Concepto y concepción de los de los derechos humanos 'Acotaciones a la ponencia de Francisco Laporta' ”, Doxa. Cuadernos de Filosofía el Derecho, n 4, 1987, p. 55) "que los derechos humanos son una categoría histórica, es una idea hoy ampliamente compartida y que esta idea se da en el tránsito a la modernidad (citando a Peces Barba, 1982) que desembocarían en las revoluciones burguesas del XVIII. Esto otorgaría a los derechos humanos un perfil ideológico definido de matriz individualista". Más adelante citando a E. Denninger (1987) sostiene que "la consideración histórica enseña que los derechos fundamentales no son la expresión, ni el resultado de una elaboración sistemática, de carácter racional y abstracto, sino respuestas normativas histórico-concretas a aquellas experiencias más insoportables de limitación y riesgos para la libertad" p. 62.

${ }^{3}$ En lo que a mí se me alcanza. Pero utilizaré un argumento de autoridad. En este mismo número de la revista Doxa, en contestación a la ponencia de Francisco Laporta, Eugenio Bulygin sostiene que “...Se me podría reprochar que esta concepción de los derechos humanos los prive de cimientos sólidos y los deja al capricho de legislador positivo. Por lo tanto, la concepción positivista de los derechos humanos sería políticamente peligrosa. Sin embargo, no veo ventajas en cerrar los ojos a la realidad y postular un terreno firme donde no lo hay ("Sobre el estatus ontológico de los derechos humanos", pp. 83 y 84, negrita mía).

${ }^{4}$ Es decir más allá de Rorty (Contingency, Ironity and Solidarity, Cambridge, Cambridge University Press, 1989) o de Butler ("Contingent foundatios: feminism and the question of postmodenism", en Seideman, S. (ed.), The postmodern turn: New perspectives on social theory, Cambridge University Press, 1994) o de Vattimo, obra citada. 
sofos, han considerado insuficientes los intentos anteriores y se han dispuesto a buscar otros nuevos. Es decir, esos fundamentos, de existir, son absolutamente contestados y por tanto se sitúan más en el terreno discusivo que en el terreno de esa esencia finalmente descubierta, del punto arquimédico situado fuera de la Historia y de las diversas redes de significación. Desde el iusnaturalismo de Grocio - el derecho natural es el derecho divino interpretado por la recta razón (Del derecho de Presa. Del Derecho de la Guerra y de la Paz. Textos de las obras "De Iure Praede" y "De Iure Belli ac Pacis, Madrid, Centro de Estudios Constitucionales, $1987^{5}$ )- , al contractualismo de Hobbes y su famoso Capítulo XIII del Leviatán -la justicia o injusticia no se encuentran la naturaleza, sino en la ley del Leviatán -, el aristotelismo de MacIntyre en After virtue -la modernidad tiene que escoger entre Nietzsche y Aristóteles-, hasta el constructivismo kantiano moderno del último Rawls -en el que justicia, persona e individuo se determinan, sostienen y explican mutuamente dentro de una tradición política, que no metafísica, democrática y constitucional ${ }^{6}$-, se han ido sucediendo las propuestas argumentativas encaminadas a fundamentar incontrovertiblemente los derechos humanos, y su universalidad ninguna de los cuales han logrado, (para mí y) para las comunidades de filósofos que lo siguen intentando, establecer esos fundamentos de forma incuestionable.

El concepto de imaginario social, en segundo lugar, parece que se puso bastante de moda en la cultura francesa de los años sesenta y setenta del pasado siglo. Hasta donde yo conozco, quien lo trató más extensamente fue Cornelius Castoriadis, no sólo pero fundamentalmente, en su obra La institución imaginaria de la sociedad ${ }^{7}$. Me conformaré aquí con una sucinta definición a cargo de Charles Taylor: "(los imaginarios sociales son) las formas en las que la gente imagina su existencia social, cómo ésta se acopla con la de los otros, cómo se relacionan con sus pares, las expectativas que normalmente se realizan y las profundas nociones normativas e imágenes que subyacen a dichas expectativas". La tesis en la que se basan estás páginas y, puestos a ello, toda mi investigación de los últimos años, es que es que un análisis de las relaciones internacionales acertado o, simplemente, plausible desde el punto de vista de nuestra disciplina, debe partir del análisis de los imaginarios sociales, o dicho en el espíritu de Skinner, de un vocabulario, de una tradición lingüística, dentro de los cuales se

\footnotetext{
${ }^{5}$ Poco más abajo añade que si no existiera el Derecho Divino, seguiría existiendo el Derecho Natural, sin más explicaciones.

${ }^{6}$ Rawls, J., "Justice as fairness: political not metaphysical", Philosophy and Public Affairs, vol. $14, \mathrm{n}^{\mathrm{o}} 3,1985$.

${ }^{7}$ Castoriadis, C., La institución imaginaria de la sociedad, Buenos Aires, Tusquets, 2007.

${ }^{8}$ Taylor, C., Modern Social Imaginaries, Durham y Londres, Duke University Press, 2004, p. 23.
} 
construyen todas las relaciones sociales. El desarrollo prolijo de dicha tesis queda para otra ocasión.

En tercer lugar, sostengo que los imaginaros sociales modernos en relaciones internacionales se construyen en torno a dos ejes: (1) el eje comunidad-estado y Humanidad una; y (2) el eje entre lo bárbaro y lo civilizado, o lo premoderno y lo moderno.

Estos dos ejes, a los que hace alusión el título de este trabajo, definen y delimitan los intentos de construcciones de órdenes mundiales, por lo menos desde el siglo XIX. Orientaron la Paz de París de 1918; la constitución de Naciones Unidas en el 45; la descolonización y, lo que aquí nos interesa, los proyectos de orden mundial forjados en los 90 del siglo XX, su continuación y cambio después del 11 de septiembre de $2001 \mathrm{y}$, obviamente, el régimen internacional actual de los derechos humanos.

A menudo los Derechos Humanos son definidos en términos propios de uno de los extremos de nuestro primer eje: es decir la cosmópolis, la Humanidad una, constituida por múltiples individuos cuyo valor moral, basado en el concepto de dignidad humana ${ }^{9}$, es el punto arquimédico de cualquier construcción moral (o eso mantienen muchos de sus defensores).

Así el valor moral de los seres humanos, pese a estar separados en diferentes comunidades políticas y, por tanto, que su felicidad o incluso su vida no valga -en la práctica- lo mismo, es absoluto e intrínseco a su misma humanidad. La violación de estos derechos así como su institucionalización, suelen ser examinados con el imaginario de los dos ejes mencionados y el resultado de tal análisis es siempre un discurso cuya idea central es el déficit: de estatalidad, de civilización, de cosmopolitismo, de modernidad, de accountability, de despatrimonialización de lo público, etc. Es decir, en términos de nuestro segundo eje, de atraso $^{10}$.

Por último, nos quedaría discutir el adjetivo moderno y no lo voy a hacer por pura incapacidad de definir semejante término. Me interesa, sin embargo apuntar la discusión sobre si la modernidad es occidental en su origen y concepción (surgida en la Europa Occidental de los siglos XVI, XVII, XVIII, etc.) y en su culminación (el mundo occidental democrático y desarrollado) o hay diversas mo-

\footnotetext{
${ }^{9}$ Según la lectura de Oliver Sensen (obra citada, p. 72) de estos dos documentos de Naciones Unidas la dignidad humana es un valor "inconmensurablemente más alto", "un propiedad con un valor ontológico diferente" y según estos dos documentos "los derechos humanos se derivan de la dignidad inherente de la persona humana y la Carta de NN.UU. vincula la dignidad a valor".

${ }^{10}$ Santos, B. de S. (Descolonizar el saber, reinventar el poder, Montevideo, Trilce, 2010, p. 22), distingue cinco modos de producción de ausencia: el ignorante, el retrasado, el inferior, el local o particular y el improductivo y estéril.
} 
dernidades alternativas como sostiene Taylor ${ }^{11}$. Esta última postura es muy defendible y tiene indudables ventajas: entre otras ser capaz de reconocer que en la modernidad o contemporaneidad hay diferentes formas, todas híbridas, de leer el mundo, de considerar a los seres humanos y a los grupos sociales en los que éstos se asocian. Sin embargo tan matizada opinión no creo que forme parte de la doxa -entendida como "... el conjunto de lo que se admite como evidente, $y$, en particular, los sistemas de clasificación que determina que se considera interesante y sin interés... Lo más oculto, aquello en lo que todo el mundo está de acuerdo, tan de acuerdo que ni siquiera se habla de ello, lo que está fuera de toda duda, lo evidente..."12 - dominante.

En este trabajo me centraré en el eje comunidad-estado y Humanidad una que es donde se sitúa el debate actual y trataré brevemente el eje diacrónico como procesos de imposición, apropiación, etc. ${ }^{13}$.

\section{Humanidad una y parcelada estatalmente}

Una vez explicado escuetamente el concepto de lo que aquí se entiende por imaginarios sociales, vocabularios, tradiciones lingüísticas, etc., podemos intentar deconstruir ese imaginario en términos de relaciones internacionales.

En relaciones internacionales los imaginarios sociales occidentales modernos, como ya hemos apuntado, se sitúan en dos ejes que se cruzan y, a veces, se distancian:

Un primer eje estaría constituido por el arco que se extiende desde la visión de la unidad esencial de la humanidad, del valor único de cada ser humano, de la comunidad humana como algo existente y potencialmente realizable políticamente en una cosmópolis - una democracia cosmopolita global, si seguimos a D. Held ${ }^{14}$-, hasta la terca realidad de la parcelación históricamente constante de esa humanidad una en comunidades, etnias, polis, etc. que se diferencian y se esfuerzan en diferenciarse las unas de las otras, compitiendo o luchando por el prestigio, el honor, su visión del mundo, la riqueza o el poder. En nues-

11 "Two theories of modernity", en Dilip Paraeshwar Gaonkar (ed.), Alternative Modernities, Durham y Londres, Duke University Press, 2001, pp. 183 y ss.

${ }^{12}$ Bourdieu, P., Cuestiones de Sociología, Madrid, Istmo, 1998 (ed. Francesa de 1994), p. 83

${ }^{13}$ Ya traté este segundo eje diacrónico en un artículo hace ya tiempo ("El Estándar de Civilización, La Historia de las Relaciones Internacionales, Revista Jurídica de la UAM, núm. 1, 1999). Si lo hiciera ahora, intentaría resaltar más la importancia de la dialéctica poder/resistencia-adaptación en la configuración de la sociedad internacional.

${ }^{14}$ La Democracia y el Orden Global. Del Estado Moderno al Gobierno Cosmopolita, Barcelona y Buenos Aires, Ediciones Paidós Ibérica, 1997. 
tros días, esta parcelación de la humanidad una tendría la forma de sedicentes estados-naciones, conformadores de las individualidades, y separados por fronteras simbólicas y físicas bien delimitadas ${ }^{15}$. Aquí los derechos humanos son un buen ejemplo: devienen de lo universal, pero se materializan y se ejercen estatalmente.

La idea de la humanidad una se nos presenta históricamente de la mano del estoicismo helenístico y del cristianismo primitivo de corte helenista. En la época moderna reaparece con fuerza, para no abandonarnos nunca más, de la mano de la Ilustración. Y esto, por dos vías. Como señala A. Mattelart: "Emergen dos modalidades del imaginario cosmopolita. Una, basada en la desterritorialización mercantil, que está representada por la «áulica mercantil universal» preconizada por los heraldos de economía clásica... Los revolucionarios de 1789, por su parte, piensan acerca de la unificación del mundo en términos de proyección de sus valores universales desde la nación, cuya vocación es la de sacar a la humanidad entera de su prehistoria. La ininterrumpida marcha hacia adelante de los individuos y los pueblos en busca de la libertad (¿cuál?) y la felicidad, pasará necesariamente por la «iluminación general de las mentes». A ratos divergentes, a ratos cómplices, en lo sucesivo, estos dos ideales de un espacio sin fronteras subyacerán a los intentos de construcción del nuevo vínculo social universal. Se adivina la distancia entre la perspectiva de una alteración general en la organización del globo y la singularidad de los arraigos en identidades singulares." 16

La parcelación de la humanidad en comunidades separadas puede constatarse desde que tenemos constancia de la existencia de los hombres sobre el planeta. En su forma moderna, está ligada al surgimiento de los estados en ese largo proceso de centralización y unificación patrimonial del poder y de la autoridad que se detecta en los siglos XV, XVI y XVII en Europa y que, a mediados del siglo pasado, se difunde a todo el globo en la forma del imaginario del estado-nación ${ }^{17}$.

Estas dos comunidades imaginadas -humanidad y estado-(nación)-, no son por "imaginadas" menos reales en el sentido que les da Ander-

${ }^{15}$ Estamos hablando de imaginarios sociales no de formas históricas concretas de dominación. Con esta nota me hago eco del sugerente libro de Jean Burbank y Frederick Cooper, Empires in World History, (Princeton, Princeton University Pres, 2010) y que la obra nos obligará a replantearnos cuando escribamos sobre Historia.

${ }^{16}$ Mattelart, A., Historia de la Utopía planetaria. De la ciudad profética a la sociedad global. Barcelona, Paidós, 1999. pp. 91 y 92.

${ }^{17}$ Vuelvo al libro de Burbank y Cooper. En el caso de los imperios, estaremos hablando de aquellos jerárquicos y homogeneizadores de las diferencias. 
$\operatorname{son}^{18}$, son imaginarios que funcionan como elementos reguladores ${ }^{19}$ que delimitan derechos y deberes, horizontes de expectativas, y están en la base de procesos políticos, sociales y económicos de todo tipo que marcan los extremos entre los que se mueve el cómo organizar la comunidad política. O, como sostiene Bauman, la comunidad moral no es tanto imaginada como postulada "y postulada de una manera contenciosa: un postulado siempre enfrentado a otro: un programa, una propuesta para amarrar el futuro, más que para defender o reivindicar el pasado, sobre todo, una propuesta para amarrar a un número determinado de hombres y mujeres, y subordinar sus acciones a ciertas elecciones, cuya preferencia depende del esfuerzo para hacer real la existencia postulada de la comunidad"20.

De estas dos comunidades imaginadas, el estado sigue teniendo una posición dominante. De tal manera que, la articulación política de la humanidad sigue dominada por los sedicentes estados-naciones: "Las sociedades internacionales están trabadas por estructuras constitucionales que definen la identidad social del estado y los parámetros básicos de lo que es una acción estatal justa (rightful). Estas estructuras incorporan valores constitutivos profundos: un creencia hegemónica sobre el propósito moral de una organización política autónoma y centralizada; un principio organizador de soberanía, y una norma de justicia procedimental" 21 . Esta articulación crea, a su vez, la distinción entre lo de dentro y lo de fuera, asociando orden a lo interno y desorden a las relaciones más allá de las fronteras.

Como sostengo en otro trabajo, todos los discursos modernos en relaciones internacionales, incluido el de derechos humanos, se ven atravesados por esta contradicción y dan diferentes respuestas enfatizando uno u otro de los extremos del arco que se extiende entre la unidad esencial y la parcelación real de la humanidad ${ }^{22}$. Ambas comunidades, la humana y la estatal, son esencialmente imaginadas, complejos de ideas regulativas e inconclu$\operatorname{sas}^{23}$. Son piezas esenciales de ese imaginario social. Pero tales discursos son contradictorios y, de alguna manera, excluyentes entre sí: "La idea de

${ }^{18}$ Imagined Communities. Reflections on the origins and spread of nationalism, Londres: Verso, 1983, edición revisada 1991.

${ }^{19}$ Walker, R. D. J., "Relaciones internacionales y política mundial” en C. Nasi (comp.), Postmodernismo y relaciones internacionales, Bogotá, Pontificia Universidad Javeriana, 1989, p. 69.

${ }^{20}$ Bauman, Z., Ética posmoderna, Buenos Aires, Siglo XXI, 2004, p. 54.

${ }^{21}$ Reus-Smit, C., The Moral Purpose of the State, Princeton, Princeton University Press, 1999, p. 156

${ }^{22}$ Hermanos y enemigos. Madrid, La Catarata-UAM, 2003.

${ }^{23}$ Cfr. R. J. B. Walker, obra citada. 
national-popularhood es el talón de Aquiles de las modernas sociedades liberales" 24 .

El Estado, la comunidad y la nación delimitan un dentro y un fuera de obligaciones y derechos, de intereses y posibilidades. Este imaginario social no responde necesariamente a una realidad factual, sino que es más una aspiración (o una $\operatorname{carga}^{25}$ ) que, al contrastarse con la realidad de los estados de facto, los encuentra en falta. Moralmente el estado debería ser un protector $\mathrm{y}$ un espacio donde fuera posible la realización ética o, en palabras de M. Walzer, un espacio donde poder luchar y, eventualmente, conquistar la libertad. Institucionalmente, este espacio debería parecerse a lo que Weber definió como estado: una forma eficaz de organización y una respuesta a la necesidad de pertenencia y protección. Socialmente, es el marco donde se aplican políticas públicas que benefician al conjunto de la población o, al menos, así se dice, pues este beneficio es esencialmente contestado. Internacionalmente, es la unidad básica de análisis, el protagonista casi absoluto de esas relaciones que llamamos internacionales ${ }^{26}$. En términos liberales, es un espacio donde se garanticen los derechos de propiedad ${ }^{27}$ y se disfruta de derechos políticos.

La potencial cosmópolis -la fusión del cosmos y la polis $^{28}$ - sería la expresión de la unidad esencial de los humanos y el único espacio moral verdadero, pues allí los intereses de los ciudadanos de la polis no se realizarían a costa de la vida y hacienda de otros hermanos. Institucionalmente, podría ser el gobierno mundial, el gobierno del cosmos humano o algunas instituciones que se acercaran a ese ideal sin tener sus inconvenientes ${ }^{29}$.

Es decir, el imaginario social político moderno vive en una contradicción constitutiva: los hombres son hermanos en su humanidad y enemigos en su vasallaje o ciudadanía.

\footnotetext{
${ }^{24}$ H. Arendt, The Origins of Totalitarism, citado por Appadurai, Fear of Small Numbers, Durham y Londres, Duke University Press, 2006, p. 4.

25 "El genocidio, al fin y al cabo, es un ejercicio de construcción de comunidad" P. Gourevitch, We wish to inform you that tomorrow we will be killed with our families: stories from Rwanda, 1989, citado por A. Appadurai, obra citada, p. 7.

${ }^{26}$ García Picazo, P., ¿Qué es esa cosa llamada “Relaciones Internacionales”?, Madrid, Marcial Pons, 2000.

${ }^{27}$ MacPherson, C. B., The Political Theory of Possessive Individualism, Oxford, Oxford University Press, 1964.

${ }^{28}$ Toulmin, S., Cosmopolis. The Hidden Agenda of Modernity, Chicago, University of Chicago Press, 1992.

${ }^{29}$ Que pueden venir desde la distancia entre gobierno y gobernados hasta la ausencia de un lugar donde exiliarse si tal gobierno se tornara despótico, como sostenía Kant.
} 
Esta contradicción se manifiesta en el espíritu estatista y soberanista de la Carta de NNUU frente al régimen de derechos humanos de la misma organización ${ }^{30}$, en el Derecho humanitario de guerra, en el régimen de refugiados y de asilo, etc. Quizá su manifestación más llamativa en los últimos tiempos ha sido la puesta en circulación, a raíz de la crisis de Kosovo, del concepto de guerras ilegales legítimas $^{31}$.

\section{Los leviatanes y su orden}

El orden debe ser, en palabras de Bull, mundial e internacional. Mundial pues un orden para toda la humanidad, internacional porque la humanidad está organizada en estados y éstos constituyen un sistema o una sociedad.

La estatalidad, en términos internacionales, soberana, independiente e igual, es central, pues no conocemos otra forma de organización política de la comunidad, salvo aquellas que existieron en el pasado y fueron superadas y arrumbadas por la Historia ${ }^{32}$. El estado es el ámbito que tenemos para buscar la vida buena, y su propósito moral es proporcionar seguridad (frente al miedo hobbesiano o al miedo liberal de Shklar ${ }^{33}$ o Gray), bienestar y sentido de pertenencia (en disputa con el pueblo o la nación). El estado es normativamente el guardián y el defensor de nuestra propia doxa, de nuestros derechos -se entiendan como se entiendan-, de nuestra forma de vida y de nuestra identidad colectiva. Esta comunidad imaginada es limitada, soberana e imaginada como unitaria porque a pesar de "las divisiones internas se concibe como una camaradería horizontal y profunda" ${ }^{34}$

De esto se derivan varios hilos. En primer lugar el concepto de estado puede desagregarse y podemos hablar de "la idea del estado" 135 como el imaginario de una territorito y una población definidos interna e internacionalmente, del gobierno de dicho estado (teniendo en cuenta que, aunque raras veces, puede darse una idea del estado sin un gobierno mínimamente efectivo), de los aparatos del estado, del

${ }^{30}$ Ruiz-Giménez, I., Historia de la intervención humanitaria, Madrid, La Catarata-UAM, 2006.

${ }^{31}$ Que aparece por primera vez como justificación a posteriori del bombardeo de Serbia y la intervención en Kosovo. Ver Goldstone, R. J., Kosovo: An Assessment in the Context of International Law. Nineteenth Morgenthau Lectures, Nueva York, Carnegie Council on Ethics and International Affairs, 2000.

${ }^{32}$ Otra vez Burbank y Cooper. Según su tesis los imperios perduraron y fueron protagonistas hasta nuestros días.

${ }^{33}$ Shklar, J., "Liberalism of fear", en Rosenbhaum, N. L., Liberalism and modern life, Cambridge Ma., Harvard University Press, 1999.

${ }^{34}$ Anderson, B., obra citada, p. 7

${ }^{35}$ Buzan, B., Peoples, sates and fear, Londres, Harvester Wheatsheaf, 1991. 
pueblo o pueblos que ese estado dice representar y defender, y de la nación que reclama encarnar ${ }^{36}$. Todos estos aspectos desagregados del estado pueden, raramente, coincidir, o no coincidir, pero en el imaginario social moderno, en su horizonte de expectativas, la coincidencia - el fit-forma parte de la doxa.

En segundo lugar, el estado - postulado y como horizonte regulativo- es la expresión de un pueblo o de una nación y, por el contrario, cada nación o pueblo debe tener un estado. Si seguimos a Renán la esencia de la nación "es que todos los individuos tiene muchas cosas en común y que todos se sienten obligados por las mismas $\operatorname{cosas}{ }^{\prime 37} \mathrm{y}$, especularmente, todos aquellos que tienen algo en común y se sienten obligados por ciertas cosas que los diferencian de otros, pueden reclamarse nación y exigir una estatalidad propia. De tal presupuesto del imaginario social moderno se derivan tres corolarios; (1) el principio de autodeterminación, como principio moral, no necesarísimamente como principio del derecho positivo, y su consecuencia la lucha por delimitar qué es un pueblo, qué es una nación, etc.; (2) la idea de ciudadanía, es decir la delimitación del nosotros y del los otros, de aquellos que pertenecen y aquellos que no, de los que poseen derechos y deberes y de los que pueden ser acogidos pero no incluidos; y (3) la idea de frontera, la imaginaria línea sólo visible en las representaciones cartográficas, que delimita milimétricamente lo de dentro y lo de fuera, la nación y la no nación, el territorio de los ciudadanos y el de aquellos que, por nacimiento o pertenencia a lo situado unos metros más allá, carecen de ese estatus.

Pero cabe apuntar que la modernidad trajo consigo el ideal normativo de la separación de lo privado y lo público en materias de conciencia y en materias de patrimonio. En lo primero el estado moderno es secular o camina por la línea de la secularización. En palabras de Rawls no hace falta acuerdo entre los ciudadanos sobre las concepciones del bien, sólo procedimientos claros que se asienten en el mínimo común denominador de las diversas creencias presentes ${ }^{38}$. Religión, identidad étnica, costumbres o cultura no tienen que desaparecer siempre y cuando no se conviertan en instrumento de lucha política, siempre que queden relegadas al ámbito de lo privado.

Finalmente como ya mencionara $\mathrm{C}$. Schmitt esta reclusión de la religión al ámbito de lo privado vino acompañada de una secularización de los conceptos teo-

\footnotetext{
${ }^{36}$ Los derechos humanos se sitúan en la forma de gobierno y dentro de ésta en la estructura y función de los aparatos del estado, no cuestionan, en principio, la idea del estado a la que me he referido en el texto. El principio o derecho de autodeterminación fue entendido, por lo menos hasta la crisis de Kósovo, como un principio anticolonial: es decir, aplicable sólo a los territorios bajo dominio colonial.

${ }^{37}$ Citado por B. Anderson, Imagined Communities, p. 6.

${ }^{38}$ Rawls, J., Political Liberalism, Nueva York, Columbia University Press, 1993.
} 
lógicos ${ }^{39}$. Esta secularización es central en la fundamentación filosófica de los derechos humanos. Al no poder recurrir a un ser supremo que dota de dignidad a los seres humanos "por haber sido hechos a su imagen y semejanza", quedan muy débiles las bases del Derecho Natural y los filósofos llevan siglos buscando esa fundamentación secularizada, a mi modo de ver infructuosamente, de tal manera que ahora ya se afirma que no es cuestión de fundamentar su base filosófica si no de ponerlos en práctica.

Caben tres últimas salvedades. En primer lugar, incluso en los imaginarios menos estatistas, más liberales (libertarians), más partidarios de una estado mínimo, la defensa del país es una precondición necesaria de cualquier experimentación social: incluso si se pone en cuestión la pretensión tradicional del estado de ser el portador de una elevado proyecto moral, el estado aún conserva la mínima misión moral -lo que Reus-Smit llama the moral purpose of the state ${ }^{40}$ - de garantizar la unidad de la sociedad, de permitir a las gentes que definan y persigan sus propios proyectos morales, de que ejerzan sus derechos sin intromisiones y de que cumplan con sus deberes.

En segundo lugar, cuando hablamos de comunidades imaginadas -la estatal y la cosmopolita- hay que tener en cuenta que los estados-naciones lo son, de haberlos estrictou sensuo, en una pequeña parte del globo. Las Relaciones Internacionales como disciplina y en general las ciencias sociales se han construido sobre mitología del estado. Para un tanto por ciento elevado de la humanidad la comunidad estatal, no sólo es un postulado imaginado y regulador, sino algo aún más lejano: "una aspiración (¿?) futura ${ }^{41}$, más que una realidad práctica". Un proyecto de determinadas élites (sobre todo en los años de las independencias) y de la comunidad internacional (léase comunidades de donantes e instituciones internacionales), más que realidades sobre el terreno; algo que a lo que temer más un defensor de derechos .

Por último, cabe afirmar, que está latente en el imaginario social moderno la idea de que el estado, a veces, no es la solución a las necesidades de seguridad, bienestar y pertenencia sino, más bien, la esencia misma del problema. Todos los discursos y argumento recientes sobre el deber de proteger tratan esta posibilidad. En este sentido, la garantía de los derechos humanos por el estado en cuestión sería la vara de medir el grado en que el Estado no protege sino amenaza. 2001 .

${ }^{39}$ Schmitt, C., Carl Schmitt, Teólogo de la Politica (selección de textos), México, F. C. E.,

${ }^{40}$ Reus-Smit, C., obra citada.

${ }^{41}$ Mann, M., “¿Ha terminado la globalización con el imparable ascenso del Estado nacional?, en Monedero, J. C., (ed.), Cansancio del Leviatán, Madrid, Trotta, 2003, p. 238. 


\section{La humanidad una}

La idea de la humanidad como un todo, por muy naturalizada que esté, no deja de ser otra como comunidad imaginada, pero que funciona como referencia (doxa) y como contrapunto del estado. Como idea no deja de ser una construcción social, histórica, por vasta que sea su base biológica.

La expresión política de semejante imaginario social ha sido el cosmopolitismo, que T. Pogge, caracteriza por el individualismo (en última instancia las unidades morales son los seres humanos), su universalidad (este estatus moral se predica de cada ser humano de forma igual) y su generalidad (y en toda circunstancia, de tal manera que "la idea central del cosmopolitismo moral es que cada ser humano tiene un estatus moral global") ${ }^{42}$.

La extensión de esta idea de humanidad a todo ser humano es relativamente reciente. Cabría hablar de lo que Bourdieu llamaba "condiciones históricas de posibilidad" $"$, de las génesis social de las formas de pensamiento, de las "diferentes disposiciones cognitivas hacia el mundo de acuerdo a las diferentes situaciones históricas y sociales" ${ }^{\prime 4}$, de las diferentes formas de construir el mundo (worldmaking) de acuerdo con esas condiciones. Fue el contacto masivo y continuado con el otro, su conocimiento directo o indirecto, el que posibilitó y creó, desde la perspectiva de este cosmopolitismo cristiano helenístico, este imaginario de una humanidad una, de las obligaciones que tenemos hacia nuestros congéneres y de los derechos que esperamos que nos sean respetados por otros por el simple hecho de ser humanos.

La lucha sobre dónde situamos la comunidad -en el estado o en una unidad mayor (cristiandad, res publica cristiana, sistema europeo de estados, civilización, cosmópolis, etc.)- tiene una larga historia. La Humanidad como horizonte político ya está explícita en Marco Aurelio, ejemplo - eso se dice- del estoicismo romano, cuando se identifica como romano por ser Antonino y como hombre por ser parte del género humano. Y cobró tintes políticos con la Ilustración y con las transformaciones sociales revolucionarias que fueron su herederos: la revolución americana, la francesa y, en última instancia, la rusa.

El hecho de que el sistema de estados venciera a los intentos de estas revoluciones de invocar la unidad de los ciudadanos o de los proletarios por encima de las fronteras estatales heredadas del Antiguo Régimen, no obsta para que la idea de la humanidad -o de aquella parte del ella que no es un obstáculo- por defensa de privilegios, ignorancia o maldad, que impida que la

\footnotetext{
${ }^{42}$ Pogge, T., “Cosmopolitanism and Sovereignty”, Ethics, n 103, 1992, pp. 48 y 49.

${ }^{43}$ Pascalian meditations, Cambridge, Polity Press, 2003, p. 75.

${ }^{44}$ Ibid., p. 16.
} 
potencia se convierta en realidad- quedara firmemente anclada en el imaginario colectivo moderno. La Humanidad, como comunidad polítca no podía proporcionar la seguridad que se suponía proporcionaba el estado, ni era factible el bienestar de la mayoría fuera de los marcos estatales, ni podía proporcionar sentimientos de pertenencia tan fuertes como los nacionales, pero ha seguido presente como contraimaginario de la parcelación de los seres humanos en estados.

En la Segunda Guerra Mundial venció un estatismo cualificado -por los juicios de Núremberg que dictaminó crímenes de lesa humanidad y por la consolidación de los bloques-y se consolidó con la descolonización. Así Naciones Unidas es profundamente estatista en su Carta pero propició la (universal) Declaración de Derechos Humanos de 1948, dando así lugar a dos regímenes en disputa ${ }^{45}$.

\section{Estatismo soberanista y cosmopolitismo humanitario}

La comunidad imaginada de la humanidad argumenta de forma contradictoria con la comunidad imaginada de la nación. De tal manera que en lo que respecta a las relaciones internacionales unas veces se argumenta comunitariamente y otras con argumentos cosmopolitas: se da preeminencia al interés nacional o al interés de la humanidad. Ya hemos mencionado que los derechos humanos están muy estrechamente ligados y surgen de la universalidad -sea ésta la de la dignidad humana, la de la racionalidad de los seres humanos o cualquier otra-pero se realizan estatalmente. Si ponemos un ejemplo y nos remitimos a la figura de la intervención humanitaria se argumenta en términos de, por una parte, sufrimiento humano o de la violación de esos derechos y, por otra, en términos de seguridad de los combatientes propios. En la práctica esto puede suponer evitar limpiezas étnicas con bombardeos a 5.000 pies de altura, o ir a derrocar tiranos siempre que esto no suponga excesivas bajas propias. La prudencia, la gran virtud realista, se cuela por la ventana del discurso cosmopolita.

Estamos ante un problema de incoherencia y conflicto dentro de los imaginarios sociales, pero con la peculiaridad de que esta incoherencia es estructural e inevitable en las condiciones actuales, pues remite a las obligaciones debidas a dos comunidades imaginadas que nos llevan en direcciones contrapuestas. El imaginario social cosmopolita -presente en el imaginario social modernoreconoce que estamos en un mundo de estados que no debería serlo, un mundo que nos hace problemático situar las fronteras simbólicas, físicas y demográficas del nosotros.

${ }^{45}$ Ver Ruiz-Giménez, I., obra citada, p. 16. 
En ese punto los gobernantes se encuentran en una situación difícil ante los imaginarios sociales de los ciudadanos: deben defender los intereses nacionales siendo a la vez cosmopolitas. El público -sus votantes- puede ser incoherente, no porque lo sea de por sí, sino porque vive en dos imaginarios sociales contradictorios, y quiere que se satisfagan las obligaciones frente a la comunidad y al mismo tiempo, aunque en menor medida, las que tenemos hacia toda la humanidad. De tal manera que las políticas públicas siempre serán incoherentes y siempre estarán sujetas a las críticas, por no haber hecho suficiente por los desfavorecidos del mundo y/o por haber incurrido en costes nacionales demasiados altos. Tanto más cuanto que la justificación pública de los actos de gobierno y la reelección de los magistrados forman parte del imaginario social político moderno.

En cualquier caso la cosmópolis imaginada está en lucha con la idea de estado-nación... ambos son parámetros de un orden en disputa y aparecerán como dominantes en uno u otro momento. Estas luchas se formulan en diversos vocabularios: comunidad global, orden, interés del estado, acuerdo sobre la necesidad de gobernanza global pero desacuerdo sobre su alcance, métodos y medidas.

Cabe reseñar que ambas ideas-fuerza, estado y cosmópolis, pueden ser liberadores y/o opresores según las circunstancias históricas o los grupos en conflicto. Mientras sean ideas que se mantienen en el imaginario social, tradición lingüística o cultural, conviven, a pesar de su incoherencia, con una cierta dignidad. Sin embargo tan pronto como los grupos sociales o los individuos las esgrimen como armas de lucha estas ideas, estos imaginarios, pueden convertirse en instrumentos de dominación política. Y cuando un concepto como humanidad "es usado políticamente para identificar una organización política particular, surge inmediatamente el peligro de un uso imperialista del concepto"46. No otro fue el caso de J. Solana, cuando siendo Secretario General de la OTAN, anunció la decisión de bombardear Serbia en la crisis de Kosovo, arrogándose para la OTAN la representación de la "comunidad internacional".

Stanley Hoffman tituló uno de sus libros Janus and Minerva ${ }^{47}$ dando a entender, ya en el título, que los fenómenos e instituciones políticas siempre tienen, al menos, dos caras: una positiva (¿para quién?) y otra negativa (¿para otros o para los mismos?), que como diría Weber del Bien, en política no surge necesariamente el Bien, ni del Mal, el Mal: pues el Bien (otra vez para quién) puede surgir del Mal y al contrario; que la mejores intenciones traen apareja-

\footnotetext{
${ }^{46}$ Schmitt, C..., "Ethic of State and Pluralistic State", en Mouffe, C., (ed.), The Challenge of Carl Schmitt, Londres, Verso, 1999, p. 205.

${ }^{47}$ Janus and Minerva. Essays in the theory and practice of international politics, Boulder, Westview Press, 1987.
} 
das las peores consecuencias ${ }^{48}$; que las soluciones de hoy son el germen de los problemas de mañana, etc.; que el mundo de la política es un continuo tejer y destejer; y que el destino del Hombre se asemeja más al mito de Sísifo que al de la sociedad comunista -según la concibió Marx-, o el reino de Dios en la tierra. Obviamente lo que subyace a todo lo anterior es una filosofía de la historia no teleológica, y una ontología de la cosa política como esencialmente conflictiva.

Tales ideas pueden aplicarse al estado como imaginario y como institución real y al imaginario cosmopolita y a sus prácticas. El estado soberano es una protección y una cárcel, puede ser visto como la expresión de ese imaginario de comunidad (nacional o no) y su espada y su escudo o como el patrimonio de cleptocracias y torturadores. La cosmópolis restablece muchos lazos de hermandad transfronteriza, pero puede ser (violentamente) homogeneizadora.

\section{Comunidad-Estado y humanidad una: contextos de argumentación y enunciación}

Es útil, en este sentido distinguir, a la manera de los juristas, entre el contexto de argumentación y el contexto de enunciación ${ }^{49}$.

En el primero, la apelación a la esencial dignidad de los seres humanos y al escaso o nulo valor moral de las fronteras nos remite a ese imaginario de la humanidad una y no carece de peso argumental ni de valentía moral, de la misma forma que la utopía de la paz, a la que se refiere $\mathrm{Carr}^{50}$, expresaba no sólo intereses de las potencias vencedoras, sino la profunda crisis moral que afectó a Europa tras la Primera Guerra Mundial.

La argumentación cosmopolita señala sufrimientos, problemas e instituciones que apelan a nuestra conciencia moral, a la red de significados cognitivos, normativos $\mathrm{y}$ afectivos que del imaginario social moderno que convierten el ser en el deber ser, o en no deber ser.

En este nivel de contexto de argumentación, el discurso cosmopolita, obviamente, no se ve así mismo en ningún caso como capaz de causar el mal. En primer lugar, porque su concepción de la historia es teleológica y progresista de raíz teológica: "El deseo revolucionario de realizar el reino de Dios es el punto

\footnotetext{
${ }^{48}$ Schlesinger, A. M., Los ciclos de la historia americana, Madrid, Alianza Editorial, 1988.

${ }^{49}$ Debo a Carlos Expósito (UAM) el conocimiento de esta formulación. Ver Atienza, M., Las razones del Derecho. Teoría de la argumentación jurídica, Mexico D. F., Universidad Autónoma Nacional de México, 2007.

${ }^{50}$ Carr, E. H., La crisis de los veinte años (1919-1939). Una Introducción al estudio de las Relaciones Internacionales, Madrid, Los libros de la Catarata, 2004.
} 
elástico de toda cultura progresista y el comienzo de la historia moderna". ${ }^{11} \mathrm{Y}$ en ese desplegarse hacia el reino de Dios (o hacia el reino de la libertad que Marx predicaba) la historia tiene que superar los obstáculos de la ignorancia, la maldad o, en definitiva, el atraso. Y aunque la Primera Guerra Mundial había generalizado la sospecha de que la armonía de intereses sustentada en las alas de la mano invisible smithiana o del plan oculto de la Naturaleza kantiano, podía ni ser tan evidente ni tan históricamente eficaz; que la política-las relaciones sociales-no eran, en principio, ontológicamente conflictivas, pero si lo eran en el tiempo pasado, en el presente y (previsiblemente) en el futuro; y que quizás había que empujar manu militari el avance de la historia, del ideario cosmopolita, que, no por ocultar púdicamente su filosofía de la historia, deja de apelar constantemente a todos nosotros.

Es en su contexto de enunciación ${ }^{52}$ del discurso cosmopolita -en su diseño de prácticas para la política mundial-, donde la enseñanza de Carr adquiere más significado. Nuestro autor nunca sostuvo que las potencias satisfechas no se creyeran la idea de la paz como bien supremo internacional sino que señala, al estilo de K. Manheim ${ }^{53}$, que el proceso histórico social, la memoria del pasado y la situación presente influyeron en la formulación de los fines y valores supremos.

De la misma forma hoy podemos ver que el imaginario social cosmopolita está desigualmente repartido en el mundo. Salvando las distancias, podríamos hacer una analogía con la clasificación de los estados actuales en posmodernos, modernos

${ }^{51}$ Löwith, K. citando a F. Schlegel en, El hombre en el centro de la historia. Balance de la filosofia del siglo XX, Barcelona, Heder, 1998, p.335.

${ }_{52}^{5}$ La visibilización de lo que llamo, no originalmente, desde luego, contexto de enunciación me parece muy importante. Sostengo que el contexto de enunciación ni invalida ni debilita los argumentos (contexto de argumentación), pero creo que las ideas o las redes de significado dan lugar a muchos procesos -forman parte de muchos procesos- buenos y malos, justos e injustos (aquí me contradigo a mi mismo, adjetivando lo que solo puede ser adjetivado lingüísticamente, para dejar clara mi posición) pues a lo Hobbes creo que en la naturaleza no existe ni la justicia ni la injusticia. El contexto de enunciación nos remite a: "la teoría, la filosofía están siempre implicadas en el poder... que el aparato filosófico... siempre está ejerciendo poder" (Butler, J., obra citada "Contingent foundatios...,", p. 156 ).

${ }^{53}$ Manheim, K., Ideología y utopía, (Barcelona, Gedisa, 1999)“Sin embargo, cuando entramos en la zona de lo político, en que todo se halla en proceso devenir y en que el elemento colectivo en nosotros, considerados como sujetos cognoscentes, ayuda a forjar el proceso del devenir, en que el pensamiento no es contemplación desde el punto de vista de un espectador, sino más bien activa participación en el propio proceso y re-creación de éste, parece surgir un nuevo tipo de conocimiento, verbigracia, aquel en que la decisión y el punto de vista se hallan inseparablemente unidos", p. 150.

"La génesis social e histórica de una idea carecería de importancia en cuanto a su validez última, si las condiciones sociales y temporales de su aparición no tuvieran efecto alguno sobre su contenido y su forma", .p 236. 
y premodernos de R. Cooper ${ }^{54}$ : desde luego no está implantado el discurso cosmopolita de la misma forma en los países escandinavos, o en Europa, e incluso en Estados Unidos - añadiéndole aquí el matiz de su sentido del excepcionalísimo norteamericano, su destino manifiesto y que se ve asimismo casi como la encarnación del Reino de Dios en la tierra- que en países como Rusia ${ }^{55}$, China o Argentina ${ }^{56}$. La significación moral y política de las fronteras es distinta para quienes puede fácilmente traspasarlas, que para aquellos para los que las fronteras son una barrera simbólica - pero barrera al fin y al cabo- que difícilmente pueden traspasar, pero que, al mismo tiempo, protegen determinada idea del estado. La denostada idea de estado-nación sigue siendo un ideal a conseguir en numerosos sitios del planeta. No creo que sea necesario poner ejemplos, que pueden encontrarse en la prensa diariamente. Simplemente llamar la atención sobre la suspicacia y el sarcasmo con los que sociedades del Sur escuchan este seráfico discurso cosmopolita de las sociedades de la abundancia.

Cabe aplicar la misma distinción al estatismo soberanista. Su contexto de argumentación puede sonar hoy en los países occidentales avanzados, y en determinados círculos y en determinadas circunstancias, como algo caduco. De otro tiempo. Ese nacionalismo metodológico del que abomina U. Beck ${ }^{57}$ que no permite entender el mundo, que castra la empatía natural que sentimos por nuestros congéneres y que carece de sentido en un mundo globalizado, donde el acotamiento del tiempo y el estrechamiento del espacio, posibilita ver en tiempo real el sufrimiento que se produce a miles de kilómetros. Pero, aun así, el núcleo de la argumentación soberanista es tan sólido como en tiempos de Carr o Morgenthau:

${ }^{54}$ The Postmodern State and the World Order, Londres, Demos, 1996, p. 269.

${ }^{55}$ Lavrov, S. "La nueva Rusia en el mundo contemporáneo", El País, 6 de octubre de 2006.

${ }^{56}$ Discurso de la Presidenta Cristina Fernández de Kirchner en laAsamblea Legislativa, lunes, 10 de diciembre de 2007: "El Presidente, que está sentado a mi izquierda, junto a todos los argentinos cambió en estos cuatro años y medio ese escenario que teníamos aquel 25 de mayo. Lo hizo en nombre de sus convicciones que son las mías y las de muchísimos argentinos que siempre creímos en el país y en sus hombres y en sus mujeres, en el pueblo y en la Nación, palabras que tal vez en tiempos de la globalización no suenen bien o suenen raro al menos, pero a poco de conocer a los países con más desarrollo económico y social e indagar en las claves de su crecimiento y de su desarrollo, uno puede encontrar en la defensa irrestricta de sus propios intereses, como Estados y sociedades, la clave de ese avance, la clave de ese desarrollo.

Por eso, pueblo y nación en tiempos de globalización siguen más vigentes que nunca... (mi obligación es) representar los intereses de los argentinos...Quiera Dios y me ilumine para que me equivoque lo menos posible, que me ayude a escuchar, que me ayude a decidir. Lo voy a hacer como siempre he hecho todas las cosas que he emprendido en mi vida: con mis convicciones, con mis ideas y, por sobre todas las cosas, con mi inmenso y eterno compromiso con la Patria" en http://www.casarosada.gov.ar.

${ }^{57}$ La mirada cosmopolita o la guerra es la paz, Barcelona, Paidós, 2005. 
la humanidad está dividida en estados discretos y es, todavía, dentro de ellos donde se puede luchar y eventualmente conseguir la libertad y/o el bienestar, como diría M. Walzer ${ }^{58}$.

Hedley Bull, escribió a finales de los setenta un bonito artículo titulado "The State's positive role in world affaris ${ }^{59}$. Como bastante se ha dicho ya sobre el Leviatán, me limitaré aquí a recoger la argumentación de Bull. Nuestro autor defiende su tesis con cinco argumentos y en apenas 12 páginas.

En el primer argumento, dirigido contra los que anunciaban que ya se estaba yendo más allá del estado, Bull sostenía que los estados estaban en el mundo para quedarse, no indefinidamente, como cualquier otra forma histórica de organización de la polis, sino en el futuro previsible. Es más, sostenía que el papel del estado no hacía más que crecer tanto dentro como fuera del estado mismo y no veía ninguna alternativa que pusiera en cuestión su hegemonía como forma de organizar a la comunidad. En segundo lugar, Bull argumentaba que la guerra, la injusticia económica y el desastre ecológico tenían causas más profundas que la organización del mundo en estados. En tercer lugar ${ }^{60}$, nuestro autor sostenía que los críticos del estado olvidaban las positivas aportaciones del estado y del sistema de estados al orden internacional: entre otras que los estados "habían cooperado entre ellos en el mantenimiento del orden interestatal, o internacional, habían sustentado la autoridad doméstica y establecido reglas de coexistencia". De hecho el desafío a la idea del monopolio legítimo de la violencia por parte del estado, estaba llamada a causar un gran desorden internacional. No olvidemos, apunto yo, que las revoluciones implican desorden nada más que momentáneamente, y que su papel o pretensión es sustituir un orden por otro considerado más justo. En cuarto lugar, señalaba que no había consenso sobre las alternativas al estado como expresión de la polis. Por último, argumentaba sobre lo que en otra parte se dice "que las buenas fronteras hacen buenos vecinos" y, en cualquier caso, el mantenimiento del orden mundial no pasaba por eliminar las fronteras "sino por encontrar un modus vivendi... entre los diferentes valores e instituciones que necesariamente tiene que coexistir"61.

Si nos referimos al contexto de enunciación de la idea y la práctica del estado, deberíamos afirmar, una vez más, el carácter contingente de esta forma de organización de la comunidad política nacida en Europa a partir del siglo

${ }^{58}$ Esta cita no textual de Walzer aparece constantemente. Me parece muy esclarecedora por su indeterminación, su claridad a la hora de exponer que la libertad se conquista y que ésta, hoy por hoy, sólo se puede lograr dentro de una comunidad.

59 "The State positive role in world affairs", en Falk, R., et al., (eds.), Towards a just world order, Boulder, Westview, 1982.

${ }^{60}$ Ibid., p. 65.

${ }^{61}$ Ibid., p. 73. 
XVII ${ }^{62}$. Sería interesante, si pudiéramos escribir historia contrafáctica, narrar la historia de aquellas alternativas al estado que no cuajaron o que fueron derrotadas, pero no podemos. Así deberemos referirnos a lucha de señores de la guerra medievales para sobresalir en poder y riqueza sobre sus vecinos o coetáneos, del proceso de concentración del poder, del ya príncipe, frente a otros estamentos y frente a sus vecinos, que tan acertadamente describió Maquiavelo. Del papel de la violencia en la organización del estado: por la guerra y para la guerra ${ }^{63}$. De cómo las revoluciones, surgidas en territorios ya demarcados por el Antiguo Régimen, pasaron de llamamientos universales al derrocamiento de los tiranos o del capitalismo, a la convivencia estatal o a los proyectos imperialistas de Napoleón y, según Burbank y Cooper, de la URSS ${ }^{64}$.

Valga como ejemplo el contexto de enunciación del realismo político en los años cincuenta en Estados Unidos. Robert Jervis dejó meridianamente claro este contexto de enunciación o, por lo menos de consagración del realismo político de los 50 , o de una versión mecanicista, materialista y desprovista de sus fundamentos éticos, filosóficos, históricos y agónicos. Esta teoría estatocéntrica proporcionó a los dirigentes estadounidenses que se enfrentaban con algo desconocido para ellos, su papel de superpotencia en el contexto de la guerra fría, de un lenguaje moral-aquél que los emigrados alemanes llevaron al exilio y que recogía la experiencia del sistema de estados europeos- que justificaba y paliaba el moralismo imperante en la política exterior norteamericana ${ }^{65}$. Fue un discurso hegemónico durante décadas y, ni mucho menos, ha desaparecido, sino que se entremezcla, bien o mal, con el $p a-$ thos cosmopolita de las sociedades satisfechas, de los valores posmateriales.

\section{Procesos de imposición, resistencias y reapropiaciones}

La relación de estos imaginarios sociales básicos se articula, históricamente, en la larga duración braudeliana (y en la corta duración de la extensión universal del estado-nación como forma de organizar la comunidad política) y, geográficamente, en la expansión europea, en la transformación del sistema europeo

${ }^{62}$ Esto de poner fechas a largos procesos es como ponerle vallas al campo. Aquí me referiré a la convencional fecha de 1648 como origen del estado moderno.

${ }^{63}$ Tilly, C., "War-making and state-making as organized crime", en Evans,P., Ruesdeschemeyer, D. y Skocpol, T. (eds.), Bringing the state back in, Cambridge, Cambridge University Press, 1985.

${ }^{64} \mathrm{La}$ revolución francesa, en un primer momento fue capaz de combinar ese llamamiento universal con la idea de nación y de pertenencia en la media en que ésta se entendía en términos políticos de adhesión al nuevo régimen: era ciudadano de la República cualquiera que apoyara la revolución, independientemente de su origen geográfico.

${ }^{65}$ Jervis, R., "Hans Morgenthau, Realism, and the Scientific Study of International Politics", Social research, vol. 61, $\mathrm{n}^{\circ}$ 4, 1994. 
de estados en un sistema internacional de estados y en la desaparición de los imperios coloniales ${ }^{66}$.

Si a la historia nos referimos, podemos enunciar este imaginario social básico de forma diacrónica -nuestro segundo eje- $\mathrm{y}$ veremos que las relaciones del sistema europeo de estados con otros pueblos, tanto durante su fase de formación como en su fase de consolidación, se asentaron, y se asientan, sobre una concepción dicotómica que también une a los hombres en una humanidad común y única y, al mismo tiempo, los separa en función de su grado de civilización. Así, lo que en la era de la expansión imperial ibérica era una dicotomía entre cristianos y paganos, pasa con la Ilustración a ser una diferenciación entre civilizados y bárbaros, en las teorías del desarrollo de los 60 entre modernos y tradicionales, y entre desarrollados y subdesarrollados en la actualidad: "Era el tiempo, tiempo geológico, tiempo evolutivo, lo que separaba al europeo del otro". ${ }^{67}$

Estos dos ejes -comunidad-estado y Humanidad una, por un lado y primitivismo-tradición y modernidad, por otro- que se entrecruzan y articulan forman el imaginario social moderno occidental de relaciones internacionales. Pero este imaginario, como ya hemos visto, no está aislado: en primer lugar, porque una de sus causas una de las condiciones de posibilidad de su formación- es el encuentro con el otro sobre todo desde el siglo XV en adelante; y, en segundo lugar, porque se expandió de la mano del imperialismo europeo a todo el globo. Lo que se deduce de ambas premisas anteriores es que subyacente a estos ejes existe innumerables procesos de conflictividad, de resistencia y acomodación, procesos donde se pueden identificar - a grandes rasgos y con numerosas zonas grises- vencedores y vencidos, y así hasta nuestros días. El poder material, simbólico, ideológico, científico, etc.... que se expandió por el mundo no lo hizo a la manera de un suave flujo, sino derrotando resistencias, conviviendo con ellas, creando nichos de marginación, o aceptando que los vencidos aprovecharan las brechas, para su propio beneficio material y espiritual. Resistencias, escaqueos, imitaciones y acomodaciones a la modernidad occi-

66 "A finales de siglo [XIX] esto [la idea de un Derecho de Gentes distinto según las civilizaciones] no parecía ya satisfactorio, el objetivo era un orden legal internacional universal. La idea de que el mundo pudiese estar dividido por el eje central civilizados / no civilizados, y de que principios legales generales uniesen a ambas esferas, aunque de diferente manera, era la forma más común de cuadrar el deseo de un derecho universal con las condiciones extremadamente diversas. La proporcionalidad y la necesidad gobernarían el uso de la fuerza en todas partes, pero significaría cosas diferentes entre los civilizados y entre los civilizados y los no civilizados", Kennedy, D., The Dark Sides of Virtue. Reassessing International Humanitarism. Princeton. Princeton University Press, 2005. p. 248.

${ }^{67}$ McGrane, B., Beyond Anthropology. Society and the Other, Nueva York, Columbia University Press, 1989, p. 77. 
dental homogeneizadora que propiciaba y fortalecía la jerarquía de poder material y simbólico allí donde tenía su origen.

En este entramado, como ya hemos dicho, se sitúan los derechos humanos individuales, universales y generalizables, pero deben ser recogidos en las legislaciones, deben ser respetados por los gobiernos y aparatos del estado, siempre particulares.

Históricamente estos dos ejes - estado-humanidad y salvaje-civilizado-han dado lugar a procesos relacionales -disciplinamiento, reconocimiento, reapropiaciones y resistencias- de larga duración, en sentido braudeliano, que se redolaban al calor de cada coyuntura histórica de media duración. Nos interesa destacar ....: (1) las políticas de disciplinamiento/reconocimiento que dan lugar a la conquista, la admisión o no en el sistema civilizado de estados a principios del siglo XX y después de la ola descolonizadora de los años 60 de ese siglo, hasta la puesta en la práctica de la idea de paz democrática de nuestros días ; (2) el "imperialismo del significado" de una cultura que, como diría E. Said de la cultura europea, "frecuentemente, sino siempre, se describe a sí misma de tal manera que simultáneamente valida sus propias preferencias y las defiende en conjunción con la idea del domino imperial... tal y como lo hizo Mill'"68; (3) el efecto bucle de resistencia, adopción y reapropiación de las estrategias, discursos, instituciones e imaginarios de los más poderosos y (4) los cambios en todos estos elementos fruto del contacto, lucha, acomodación y reapropiación por parte de las sociedades subalternas.

Desde luego, estos procesos afectan a los ejes de los imaginarios sociales modernos: la estatalidad, la humanidad una, lo moderno y lo tradicional. Y de forma muy directa en lo que respecta al régimen de los derechos humanos: la plasmación estatal de unos derechos de raigambre universalista; el uso del discurso de tales derechos de los individuos como forma de atacar lo que se siente como camisas de fuerza tradicionales que priman el discurso de la comunidad, la nación o el pueblo; el establecimiento de redes transnacionales de promoción de luchas contra lo que se vive como la tiranía del estado; el uso, por el contrario del discurso de la soberanía como defensa de un proyecto de construcción (autocrática) de la estatalidad, etc.

Los derechos humanos, como he mencionado reiteradamente, son parte del imaginario moderno occidental, vinculados a la idea de individuo y a la de su inherente dignidad, lo que es una forma secularizada y sin referente último en la idea cristiana de Dios a cuya imagen fueron aquellos creados ${ }^{69}$. Como cualquier otra pieza de este imaginario, de esta tradición lingüística, de ese puzle fluido y cambiante-

${ }^{68}$ Said, E., Culture and Imperialism, Nueva York, Alfred A. Knopf, 1993, p. 81.

${ }^{69}$ Aquí apelo a la autoridad de Nietzsche y Schmitt (¿anda que vaya compañeros de camase busaca éste!). Del primero, su idea del vacío de fundamentos tras la muerte de Dios; del segundo, su famosa sentencia, con la que inicia su Teología política, de que todos los conceptos políticos modernos son concepto teológicos secularizados. También cito a un compañero más aceptable: Wittgenstein. 
líquido en palabras de Bauman- que son los imaginarios sociales, es fruto de la contingencia histórica, del azar, del triunfo y, desde luego, de la derrota. Y como cualquier otra pieza de esa estructura, fuera de ésta son -en última instancia- incomprensibles ${ }^{70}$.

Pero este origen determina la formación y, por supuesto, la reapropiación del discurso de los derechos humanos. Como sostiene Boaventura de Sousa Santos ${ }^{71}$ los conceptos pragmáticos del liberalismo, como el discurso de los derechos humanos, no por ser hegemónicos, son una propiedad inalienable de ese pensamiento. Los movimientos sociales han sido capaces de usar ese discurso de manera contrahegemónica. Pero hay que tener en cuenta "que los sustantivos aún establecen el horizonte intelectual y político que define... los que es decible, creíble, legítimo y/o realista"72. El discurso contrahegemónico al refugiarse en esos adjetivos y sustantivos ejerce de franquicia del discurso liberal. Y así acepta limitar sus debates y propuestas al horizonte de posibilidades que "originalmente no es el suyo"73. El discurso crítico "asume así un carácter derivado que le permite entrar en un debate que no le permite discutir los términos del debate (mismo) y mucho menos el porqué de la opción por un debate dado y no otro"74. Existe, por tanto, una cartografía epistemológica ${ }^{75}$ que sería necesario superar para no estar atrapados por sustantivos y adjetivos dados. El discurso de los derechos humanos, hoy por hoy, sigue siendo derivado, retazos útiles, pero deslavazados, de un relato hegemónico occidentalmente moderno. Queda pendiente si los discursos y los saberes son inconmensurables (que lo son) y si existe posibilidad de traducción (que según Santos la hay, aunque con enormes dificultades).

Para Santos, muchos aspectos de la política de derechos humanos forman parte de lo que él denomina una política cultural. Así sostiene que los derechos humanos "concebidos como universales" son un arma de lucha "del cosmopolitismo del Occidente imperial" 76 . Y si uno lee libros que ya son clásicos sobre el tema, como el Rise y Sikkink ${ }^{77}$, no puede por menos de notar que las redes transnacionales de pro-

${ }^{70}$ Afirmar esto puede llevar a un relativismo cultural radical que nos podemos permitir porque, en realidad, nosotros sí disfrutamos de esos derechos.

${ }^{71}$ Santos, B. de S., obra citada.

${ }^{72}$ Ibid., p. 16

${ }^{73}$ Ibid.

${ }^{74} \mathrm{Ibid}$.

${ }^{75}$ Ibid., p. 36

${ }^{76}$ Ibid., p. 67. Y sigue: "Si observamos la historia de los derechos humanos en el periodo de posguerra, no es difícil concluir que las políticas de derechos humanos han estado en conjunto al servicio de los intereses económicos y geopolíticos de los estados capitalistas hegemónicos", pp. 69 y 70.

${ }^{77}$ Rise, T. y Sikkink, K., (eds.), The power of Human Rights, Cambridge, Cambridge University Press, 1999. 
moción de los derechos humanos se sitúan en los países occidentales y es sobre los estados de esos países sobre los que ejercen presión para que adopten la bandera de aquellos que en, supongo, el tercer mundo luchan por la democracia -y los autores no se cortan al definirla con parámetros de los países desarrollados-y los derechos humanos.

Y sin embargo, apelando o no a la idea de humanidad y de dignidad humana, están en la boca cientos de millones de seres humanos, en todas partes del globo y en los más distintos contextos. ¿Por qué ahora se presenta como universales o, más bien, se viven políticamente como universales? La respuesta más inmediata es porque el cercenamiento de la libertad ${ }^{78}$ se sufre casi universalmente, aunque en carne propia, es decir individualmente, pero ese sentimiento puede expresarse de muchas formas, e incluso vivirse de formas diferentes y sin embargo se expresa en los términos de una tradición lingüística... y esto no es (históricamente) inocente.

Cabría una segunda explicación. Los derechos humanos como otras muchas piezas del mobiliario del imaginario social occidental moderno han sido asumidos por otras culturas y otros pueblos. Es difícil ver la diferencia entre un internauta alemán, por ejemplo, y uno egipcio, salvo en que éste último ha dedicado muchas horas a fomentar una movilización antidictatorial, por ahora, triunfante.

Podríamos encontrar una última y tercera razón, el discurso de la libertad y, por tanto, el de los derechos humanos ha sufrido un proceso de reapropiación por parte de capas sociales o muchedumbres de países subalternos. "La idea de libertad tiene un atractivo universal" sostenía el consejero de Clinton A. Lake ${ }^{79}$. Tal afirmación, a la vista de los últimos acontecimientos es más acertada que nunca. Pero podríamos aquí volver a recurrir Walzer y a su metáfora sobre su participación en una manifestación en un país que no era el suyo. Los gritos de libertad en el mundo árabe pueden tener un solapamiento débil (thin) con otros gritos semejantes, y sólo en el contexto de enero y febrero del 2011 y del Norte de África, se despliega el contenido denso (thick) particular de ese tiempo y ese lugar.

El discurso de los derechos humanos, como cualquier otro fenómeno histórico, tiene siempre múltiples caras. Su defensa a ultranza puede ser una gran ayu-

${ }^{78}$...que ya es un término de una tradición lingüística, de un tiempo y de un lugar como nos dirían Quetin Skinner o Reinhart Koselleck. O por lo menos entendido tal y como se planea en el espíritu de la Declaración: como libertad negativa, en palabras de I. Berlin. Walzer (Moralidad en el Ámbito Local e Internacional, Madrid, Alianza Editorial, 1996.) nos plantea la hipótesis de que si él hubiera participado en las manifestaciones que llevaron en Checoslovaquia a la caída del régimen comunista hubiera gritado libertad como el resto de los manifestantes, pero que lo que él hubiera estado gritando lo era en términos de su moralidad thick, es decir con unas connotaciones que no eran necesariamente las mismas que las del resto de los manifestantes.

79 "Estado unidos y su posición exterior", Política exterior, vol. 35, 1993, p. 113. Agradezco a M. Fonseca el haberme recordado este artículo. 
da para aquellos que los reivindican desposeídos de ellos, pero también puede dar lugar, más allá de las primeras intenciones, a un imperialismo encubierto y espasmódico (Hume). Pero no es menos cierto que las apelaciones a la soberanía -el considerar los derechos humanos como algo ajeno y perturbador de la vida cívica del estado, argumentando en función de la pluralidad de culturas y formas de vida- puede ser el refugio de tiranos y cleptocracias o, en el mejor de los casos, de élites que quieren controlar a su población en aras de la construcción nacional, la misión histórica del pueblo, o, simplemente, el goce del poder y de la riqueza por parte de la élite que tiene secuestrado al estado.

$$
\text { 7. ... y fin }
$$

Pero aunque no hay nada natural y mucho menos inevitable en el ordenar la vida social y política en torno a los derechos humanos, "(que)... la particular lista de derechos que hoy tomamos como autoridad refleja una respuesta contingente a situaciones históricamente específicas, (que)... las concepciones contemporáneas de los derechos humanos" reflejan un largo proceso de lucha política y social que podría haber dado resultados diferentes... la historicidad contingente de las normas de derechos humanos, sin embargo no les dota de menos autoridad. No son arbitrarios, ni se pueden modificar según la voluntad, están profundamente enraizados en las construcciones sociales que dan forma a nuestra vida" 80 .

Esta larga cita de Donnelly recoge gran parte de lo que se ha querido decir en este trabajo. He intentado, además, situar los derechos humanos, en lo que respecta a su presencia en las relaciones internacionales, en el eje diacrónico de la modernidad y en el eje sincrónico de los mundos mentales, las referencias éticas últimas, los imaginarios sociales del mundo de la política mundial y sus vocabularios. Sólo creo que hay que matizar la cita anterior en un aspecto: "en las construcciones sociales que dan forma a nuestra vida". Pero si sostenemos con Seth que estamos "en una modernidad globalizada, que no universalizada" ${ }^{81}$ la nuestra de Donnelly merece ser, por lo menos, puesta entre paréntesis. Como mínimo tenemos que volver a la ya mencionada metáfora de Walzer: participamos en una manifestación donde se grita $i$ iLibertad!! Pero los diversos participantes pudieran entender diferentes cosas: libertad de expresión, libertad como autodeterminación de un grupo, libertad para practicar en el culto y en la vida pública una religión excluyen-

${ }^{80}$ Donelly, J., "The social construction of international human rights", en Dunne, T. y Wheeler, N., (eds.), Human rights in global politics, Cambridge, Cambridge University Press, 1999, pp. 84 y 85.

${ }^{81}$ Seth, S., "Once blind but now I can see: Modernity and the social sciences", International Political Sociology, vol. 7, 2013, p. 149. 
te eventualmente despótica, libertad para, como ciudadanos, arrogaros el derecho de vigilar nuestras fronteras para evitar la indeseada entrada de emigrantes ilegales o "libertad de mercado", libertad contra la tortura, etc. Por otro lado, "las construcciones sociales", donde los derechos humanos están, según Donnelly arraigados, son, al parecer, nuestras ¿pero quién es ese nosotros? Fácticamente se puede afirmar que tales construcciones con tales características son minoritarias en el planeta. Quedémonos pues en los derechos humanos como respuestas contingentes a situaciones específicas (de opresión), como picos, palas y azadones ${ }^{82} \ldots$ que algunos grupos utilizan en su lucha contra el poder ${ }^{83}$. Pero lo mismo es aplicable, no sólo a los derechos humanos civiles y políticos, sino a derechos colectivos que pueden incluso estar enfrentados con los derechos individuales, o derechos de segunda y tercera generación que no tienen porqué no estar en contradicción con aquellos... es decir se trata de un menú de discursos a la carta, ni necesariamente universales, ni necesariamente individuales... En términos de Foucault se trataría de combate, reivindicación y lucha

Pero si son y han sido instrumentos de lucha, "respuestas contingentes a situaciones específicas" ¿qué queda de su supuesta inmanencia y universalidad? Los derechos humanos -como todo discurso, postulado normativo, red de significados, práctica, etc.- no están al margen de la Historia, de la contingencia, de la doble cara (bien y mal, justo e injusto, etc...) y, desde luego, no están al margen del poder. Son un instrumento de la ideología dominante, del discurso dominante y, al mismo tiempo un instrumento - un pico, una pala y un azadón- para luchar contra ese poder. En política, estas afirmaciones no son lógicamente contradictorias, sino todo lo contrario.

\section{BIBLIOGRAFÍA}

Anderson, B., Imagined Communities. Reflections on the origins and spread of nationalism, Londres: Verso, 1983, edición revisada 1991.

Appadurai, A., Fear of Small Numbers, Durham y Londres, Duke University Press, 2006. Atienza, M., Las razones del Derecho. Teoría de la argumentación jurídica, México D.

F., Universidad Autónoma Nacional de México, 2007.

Bauman, Z., Ética posmoderna, Buenos Aires, Siglo XXI, 2004

Beck, U., La mirada cosmopolita o la guerra es la paz, Barcelona, Paidós, 2005

${ }^{82}$ Dícese que se decía que Gonzalo Fernández de Córdoba, el Gran Capitán, ante la exigencia de Fernando de Aragón de que le diera cuenta de los gastos de las guerras de Italia, contestó. "Entre picos, palas y azadones, diez millones".

${ }^{83}$ Personalmente no me convence la propuesta de Santos de crear un cosmopolitismo subalterno, obra citada, pp. 46 y 47, n. 46. 
Beitz, C., Political Theory and International Relations, Princeton, Princeton University Press, 1979.

Bull, H., "The State positive role in world affairs", en Falk, R., et al., (eds.), Towards a just world order, Boulder, Westview, 1982.

Bulygin, E., "Sobre el status ontológico delos derechos humanos", Doxa. Cuadernos de Filosofia el Derecho, n 4,1987

Burbank, J. y Cooper, F., Empires in World History, Princeton, Pricenton University Press, 2010.

Butler, J. "Contingent foundatios: feminism and the question of $<$ postmodenism>", en Seideman, S. (ed.), The postmodern turn: New perspectives on social theory, Cambridge University Press, 1994.

Bourdieu, P., Cuestiones de Sociología., Madrid, Istmo, 1998 (ed. Francesa de 1994).

Bourdieu, P., Pascalian meditations, Cambridge, Polity Press, 2003,

Castoriadis, C., La institución imaginaria dela sociedad, Buenos Aires, Tusquets, 2007.

Cooper, R., The Postmodern State and the World Order, Londres, Demos, 1996.

Cooper, R., The breaking of Nations. Order and Caos in the Twenty-First Century, Londres, Atlantic Books, 2003.

Donelly, J., "The social construction of international human rights", en Dunne, T. y Wheeler, N., (eds.), Human rights in global politics, Cambridge, Cambridge University Press, 1999

Fernández de Kirchner, C., Discurso de la Presidenta en la Asamblea Legislativa, lunes, 10 de diciembre de 2007, http:/www.casarosada.gov.ar

García Picazo, P., ¿Qué es esa cosa llamada “Relaciones Internacionales”?, Madrid, Marcial Pons, 2000.

Goldstone, R. J., Kosovo: An Assessment in the Context of International Law. Nineteenth Morgenthau Lectures, Nueva York, Carnegie Council on Ethics and International Affairs, 2000.

Held, D., La Democracia y el Orden Global. Del Estado Moderno al Gobierno Cosmopolita, Barcelona y Buenos Aires, Ediciones Paidós Ibérica, 1997.

Hoffman, S., Janus and Minerva. Essays in the theory and practice of international politics, Boulder, Westview Press, 1987.

Jervis, R., "Hans Morgenthau, Realism, and the Scientific Study of International Politics", Social research, vol. 61, no 4, 1994.

Kennedy, D., The Dark Sides of Virtue. Reassessing International Humanitarism. Princeton. Princeton University Press, 2005.

Koselleck, R., Aceleración, prognosis y secularización. Valencia, Pre-Textos, 2003

Lavrov, S. "La nueva Rusia en el mundo contemporáneo", EL País, 6 de octubre de 2006.

MacPherson, C. B., The Political Theory of Possessive Individualism, Oxford, Oxford University Press, 1964.

McGrane, B., Beyond Anthropology. Society and the Other, Nueva York, Columbia University Press, 1989

Manheim, K., Ideología y utopía, Barcelona, Gedisa, 1999. 
Mann, M., “¿Ha terminado la globalización con el imparable ascenso del Estado nacional?, en Monedero, J. C., (ed.), Cansancio del Leviatán, Madrid, Trotta, 2003.

Mattelart, A., Historia de la Utopía planetaria De la ciudad profética a la sociedad global. Barcelona, Paidós, 1999.

Peñas, F. J., "El Estándar de Civilización, La Historia de las Relaciones Internacionales, Revista Jurídica de la UAM, núm. 1, 1999.

Peñas, F. J., Hermanos y enemigos. Liberalismo y relaciones internacionales. Madrid, La Catarata-UAM, 2003

Perez Luño, A., "Concepto y concepción de los de los derechos humanos $<$ Acotaciones a la ponencia de Francisco Laporta>", Doxa. Cuadernos de Filosofía el Derecho, $\mathrm{n}^{\mathrm{o}} 4,1987$.

Pogge, T., “Cosmpolitanism and Sovereignty”, Ethics, vol. 103, nº 1, 1992.

Rawls, J., "Justice as fairness: political not metaphysical", Philosophy and Public Affairs, vol. 14, n 3, 1985.

Rawls, J., Political Liberalism, Nueva York, Columbia University Press, 1993.

Reus-Smit, C., The Moral Purpose of the State, Princeton, Princeton University Press, 1999.

Rise, T. y Sikkink, K., (eds.), The power of Human Rights, Cambridge, Cambridge University Press, 1999.

Rorty, R., Contingency, Irony and Solidarity, Cambridge, Cambridge University Press, 1989.

Ruiz-Giménez, I., Historia de la intervención humanitaria, Madrid, La Catarata-UAM, 2006.

Said, E., Culture and Imperialism, Nueva York, Alfred A. Knopf, 1993

Santos, B. de S., Descolonizar el saber, reinventar el poder, Montevideo, Trilce, 2010.

Schlegel, F., El hombre en el centro de la historia. Balance de la filosofía del siglo XX, Barcelona, Heder, 1998.

Sensen, O., "Human dignity in historical perspective", European Journal Of Politcal Theory, vol. 190, n 1, 2011.

Schlesinger, A. M., Lo ciclos de la historia americana, Madrid, Alianza Editorial, 1988.

Sklar, J., "Liberalism of fear", en Rosenbhaum, N. L., Liberalism and modern life, Cambridge Ma., Harvard University Press, 1999.

Schmitt, C., " Ethic of State and Pluralistic State", en Mouffe, C., (ed.), The Challenge of Carl Schmitt, Londres, Verso, 1999.

Schmitt, C., Carl Schmitt, Teólogo de la Política (selección de textos), México, F. C. E., 2001.

Seth, S., " $<$ Once blind but now I can see $>$ : Modernity and the socila sciences", International Political Sociology, vol. 7, 2013, p. 149

Taylor, C., Modern Social Imaginaries, Durham y Londres, Duke University Press, 2004

Taylor, C., "Two theories of modernity", en Dilip Paraeshwar Gaonkar (ed.), Alternative Modernities, Durham y Londres, Duke University Press, 2001. 
Tilly, C., "War-making and state-making as organized crime", en Evans,P., Ruesdeschemeyer D.,Skocpol,T.(eds.), Bringing the state back in, Cambridge, Cambridge University Press, 1985.

Toulmin, S., Cosmopolis. The Hidden Agenda of Modernity, Chicago, University of Chicago Press, 1992.

Vattimo, G., Adiós a la verdad, Barcelona, Gedisa, 2010

Walker, R. D. J., "Relaciones internacionales y política mundial" en C. Nasi (comp.), Postmodernismo y relaciones internacionales, Bogotá, Pontificia Universidad Javeriana, 1989

Walzer, M., Moralidad en el Ámbito Local e Internacional, Madrid, Alianza Editorial, 1996. 